\title{
Postextrasystolic changes in systolic time intervals in the assessment of hypertrophic cardiomyopathy
}

\author{
MILTIADIS A STEFADOUROS, MARIO I CANEDO, ABDULLA M ABDULLA, ELIAS \\ KARAYANNIS, ANTONIO BAUTE, MARTIN J FRANK
}

From the Section of Cardiology, Department of Medicine, Medical College of Georgia, Augusta, Georgia, USA

SUMMARY To determine if postextrasystolic changes in systolic time intervals can be used to estimate the severity of resting or provocable left ventricular outflow pressure gradient, we studied the cardiac catheterisation records of 42 patients with hypertrophic cardiomyopathy looking for instances of a single premature beat preceded by a control sinus beat and followed by a postpremature sinus beat. There were 75 such instances in 25 patients. In comparison to the control beat, the pre-ejection period in the postpremature beat was shorter by $\triangle P E P=-20 \pm 11 \mathrm{~ms}$ in 73 of 75 instances, and remained unchanged in two. The ejection time in the postpremature beat was invariably longer by $\Delta E T=37 \pm 20 \mathrm{~ms}$ (range: 10 to $85 \mathrm{~ms}$ ) and the pre-ejection period/ejection time ratio lower than control by $\Delta(\mathrm{PEP} / \mathrm{ET})=-0 \cdot 10 \pm 0.05$ (range: -0.01 to -0.25 ). Total electromechanical systole in the postpremature beat was shorter (11/75), the same (10/75), or longer (53/75) than in the control beat, the overall change being $\Delta \mathrm{EMS}=18 \pm 22 \mathrm{~ms}$. Both $\Delta \mathrm{PEP}$ and $\Delta(\mathrm{PEP} / \mathrm{ET})$ correlated poorly with the systolic peak left ventricular-aortic pressure gradient in either the control beat $(\mathrm{Gc})$ or the postpremature beat $(\mathrm{Gx})$, and also with the change in gradient $(\Delta \mathrm{G})$ from the control to the postpremature beat. In contrast, significant linear correlations were found between $\Delta E M S$ and either $\mathrm{Gc}, \mathrm{Gx}$, or $\Delta \mathrm{G}$; and also between $\Delta \mathrm{ET}$ and either $\mathrm{Gc}, \mathrm{Gx}$, or $\Delta \mathrm{G}$. Since internal and external measurements of ejection time are known to be almost identical, the regression equation $(\Delta \mathrm{G}=1.65 \Delta \mathrm{ET}-9)$ relating $\Delta \mathrm{ET}$ and $\Delta \mathrm{G}$ should be useful for the non-invasive assessment of the magnitude of provocable left ventricular outflow pressure gradient in patients with hypertrophic cardiomyopathy with spontaneous or externally-induced premature beats.

Despite a recent surge of interest in the role of rhythm ${ }^{12}$ and compliance ${ }^{34}$ disturbances in the morbidity and mortality of hypertrophic cardiomyopathy, information concerning the presence and severity of the systolic left ventricular outflow pressure gradient is still considered useful in both the diagnosis and, possibly, the management of this disease. Such information is readily obtainable by cardiac catheterisation, but the invasive nature of this procedure renders it inconvenient for serial observations on either the evolution of the disease or the effectiveness of specific treatment directed at improving or eliminating the gradient. Consequently, a non-invasive method for estimating left ventricular outflow pressure gradient was sought, and several attempts to use either echocardiography ${ }^{5}$ or the systolic time intervals ${ }^{7}$ to this end have provided Accepted for publication 25 June 1981 encouraging results.

Because of its dynamic nature and pronounced lability, the left ventricular outflow pressure gradient as usually determined at rest can hardly be considered to reflect the actual magnitude of pressure overload borne by the left ventricle under the non-basal conditions of daily activity with the attendant fluctuations of its preload, afterload, and inotropic state. Therefore, the behaviour of the left ventricular outflow pressure gradient under conditions known to aggravate it should be an important consideration in the evaluation and follow-up of patients with this disease.

The purpose of this study is to examine if the effect of postextrasystolic potentiation on the systolic time intervals provides quantitative information on the responsiveness of the left ventricular outflow gradient to positive inotropic stimulation. 


\section{Methods}

The records of all patients with hypertrophic cardiomyopathy documented by cardiac catheterisation in our institution since 1970 were retrospectively reviewed for the presence of spontaneous or induced premature beats. These beats could be either ventricular or supraventricular, since the inotropic effect of postextrasystolic potentiation is known to be related to the prematurity rather than to the site of origin of the premature beat. ${ }^{8}$ The criteria used for selection were: (1) absence of congenital shunt lesion or valvular heart disease other than mild mitral or aortic regurgitation (regurgitant fraction $<20 \%$ ); (2) absence of major arrhythmias other than occasional ectopic beats; (3) absence of atrioventricular or interventricular conduction abnormalities except for first degree atrioventricular block or right bundle-branch block, because these have no known effect on the systolic time intervals; (4) absence of left ventricular failure as evidenced by angiographic left ventricular ejection fraction exceeding 0.50 ; this was necessary because of the prolongation in ejection time known to occur with postextrasystolic potentiation in patients with left ventricular failure9; (5) simultaneous recording in the resting state, and at 50 to $100 \mathrm{~mm} / \mathrm{s}$ paper speed, of pressure signals from the left ventricle and the aorta, with adequate definition of the onset of the upstroke and the dicrotic notch on the aortic pressure signal to permit measurement of the ejection time; (6) presence of a single premature beat preceded by a (control) sinus beat and followed by a (postpremature) sinus beat; the control beat should not be preceded by another premature beat; (7) to ensure adequate degree of prematurity and also to avoid examining a postpremature sinus beat which occurred soon after the premature beat, thus being premature itself, a coupling ratio (interval between the premature beat and the preceding sinus beat, divided by control RR interval) of $<0.90$ and a compensatory pause equal to or longer than the control $R R$ interval, were arbitrarily selected as criteria for acceptance. Whenever several events fulfilling the last two criteria were identified during the same study, all were included. Out of 66 studies on 42 patients initially examined, only 27 studies on 25 patients eventually qualified, each one providing from one to eight (total $=75$ ) eligible events of postextrasystolic potentiation.

Cardiac catheterisation was carried out under premedication with pethidine $50 \mathrm{mg}$ and quinalbarbitone $50 \mathrm{mg}$ both administered intramuscularly, and included simultaneous recording of left ventricular and central aortic pressures obtained by means of a No. 6 or No. 7 NIH catheter introduced into the left ventricle through the right brachial artery, and a polyethylene (PE 160) catheter inserted into the left brachial artery by the Seldinger technique and advanced to the aorta. The diagnosis of hypertrophic cardiomyopathy was made from the left ventricular on cineangiogram using standard criteria ${ }^{10}$ and was sup- $\bar{c}$ ported in all cases by the existence of a significant (>30 mmHg) resting left ventricular to aortic systolic pressure gradient, or the development of such in response to isoprenaline infusion, Valsalva manoeuvre, or postextrasystolic potentiation after spontaneous or catheter-induced premature beats. ${ }^{11}$ Therefore, all patients had either resting or provocable left ventricular outflow pressure gradients, in addition to the angiographic criteria of the disease.

Peak left ventricular to aortic pressure gradient was the difference between the peak values for left ven- $\dot{\omega}$ tricular and central aortic pressures. The systolic time $\tilde{N}_{\mathcal{O}}$ intervals were determined from these pressure signals as previously reported. ${ }^{7}$ Thus, ejection time was 은 measured from the onset of the rapid upstroke to the nadir of the dicrotic notch on the aortic pressure signal. Whenever the upstroke included an initial slow component followed by a fast component, the point of transition from the slow to the fast component was taken as the onset of ejection. If the transi- ! tion was gradual, the onset of ejection was taken at the point where a straight line drawn tangentially to the aortic upstroke separated from the latter. The preejection period was measured as the interval from the onset of the QRS complex to the point where the rising left ventricular pressure signal reached the level of end-diastolic aortic pressure. Total electromechanical systole was the numerical sum of pre-ejection period and ejection time. All measurements were made to the nearest $0.5 \mathrm{~mm}$ which represented $10 \mathrm{~ms}$ for paper speed of $50 \mathrm{~mm} / \mathrm{s}$ and $5 \mathrm{~ms}$ for paper speed of $100 \mathrm{~mm} / \mathrm{s}$. Values for these time intervals and their ratio, measured in the control beat, were subtracted from respective measurements in the postpremature beat to provide the respective changes in the preejection period $(\triangle \mathrm{PEP})$, ejection time $(\Delta \mathrm{ET})$, their ratio $(\Delta\{$ PEP/ET $\})$, and total electromechanical systole $(\triangle \mathrm{EMS})$.

\section{Critique on methods}

The use of fluid-filled catheters for recording the left ventricular and aortic pressures introduces error in $\omega$ the measurement of the pre-ejection period, and,

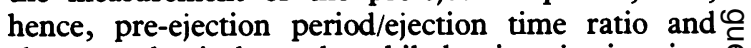
electromechanical systole, while leaving ejection time $\stackrel{\oplus}{\perp}$ unaffected. Since the level of aortic end-diastolic pres- $\cdot+$ sure is not dependent on the time lag of the aortic $\frac{\overrightarrow{0}}{0}$ catheter, the adopted definition for the termination of $\frac{\vec{P}}{\mathbb{D}}$ the pre-ejection period indicates that the error (pro- $\frac{?}{\mathbb{D}}$ longation) in pre-ejection period depends only on the $\varrho$ transmission delay of the left ventricular catheter- 
transducer system. If the measured pre-ejection period, true pre-ejection period, and left ventricular catheter system transmission delay in the control beat were represented as PEPc, PEPc', and Dc, and in the postpremature beat as PEPx, PEPx', and Dx, respectively, then:

$$
\begin{aligned}
& \mathrm{PEPc}^{\prime}=\text { PEPc }- \text { Dc } \\
& \text { PEPx }^{\prime}=\text { PEPX }- \text { Dx }
\end{aligned}
$$

Subtracting (2) from (1) results in:

$$
\mathrm{PEPc}^{\prime}-\mathrm{PEPx}^{\prime}=\mathrm{PEPc}-\mathrm{PEPx}-(\mathrm{Dc}-\mathrm{Dx})
$$

or $\triangle \mathrm{PEP}^{\prime}=\triangle \mathrm{PEP}-(\mathrm{Dc}-\mathrm{Dx})$

If the transmission delay in the control and the postpremature beat were assumed to be the same, that is $\mathrm{Dc}=\mathrm{Dx}$, then equation (3) yields $\triangle \mathrm{PEP}^{\prime}=\Delta \mathrm{PEP}$, which means that though values for pre-ejection period (and also PEP/ET and EMS) would be somewhat increased, their changes between control and postpremature beat $(\triangle \mathrm{PEP}, \Delta(\mathrm{PEP} / \mathrm{ET}), \Delta \mathrm{EMS})$ would remain unaltered. Since correlation here involved changes in, rather than absolute values of, these intervals, the catheter system delay was ignored.

The assumption that $\mathrm{Dc}=\mathrm{Dx}$ can be challenged on grounds of different left ventricular pulse transmission velocity in the postpremature beat whose faster rising left ventricular pressure in systole betrays the presence of a higher degree of harmonics in comparison to the control beat. The magnitude of error stemming from the acceptance of this assumption could be calculated by Fourier analysis of the left ventricular pressure signal and the frequency response of the catheter system. Our laboratory is not equipped to perform this analysis. Consequently the assumption $\mathrm{Dc}=\mathrm{Dx}$ was accepted on the basis of two considerations: (1) The error would probably be small. Thus, a $20 \%$ faster transmission velocity in the postpremature beat through a left ventricular catheter with, for example $10 \mathrm{~ms}$ delay, would introduce a 2 ms error in $\triangle \mathrm{PEP}$; and with unaltered ejection time the error would be similar in the case of $\Delta(\mathrm{PEP} / \mathrm{ET})$ and smaller in the case of $\triangle E M S$. An error of this magnitude is still smaller than the estimated $\pm 5 \mathrm{~ms}$ error associated with manual measurement of any time interval at a paper speed of $100 \mathrm{~mm} / \mathrm{s}$. (2) The results and conclusions would only be applicable to similarly measured time intervals, based on the same assumption.

\section{Statistical analysis}

The least square method for linear regression analysis was used to correlate each of these changes with the left ventricular aortic pressure gradient in the control beat $(\mathrm{Gc})$, the postpremature beat $(\mathrm{Gx})$, and the change in gradient $(\Delta G)$ between control and the postpremature beat. All time intervals are rounded to the nearest millisecond. All values are reported as mean \pm standard deviation.

\section{Results}

These are listed in detail in Table 1. A statistical matrix is presented in Table 2, and typical examples of the effect of postextrasystolic potentiation on systolic time intervals are shown in Fig. 1 and 2.

In comparison to the control beat, the pre-ejection period on the postpremature beat was found to be shorter in 73 instances and unaltered in the remaining two instances. The amount of abbreviation was $\triangle \mathrm{PEP}=-20 \pm 11 \mathrm{~ms}(\mathrm{p}<0.001)$, and ranged from 0 to $-50 \mathrm{~ms}$. For the ejection time, a prolongation was noted in all 75 instances between the control and the postpremature beat. The amount of prolongation was $\Delta E T=37 \pm 20 \mathrm{~ms}(\mathrm{p}<0.001)$, ranging from 0 to $85 \mathrm{~ms}$. Without exception, the pre-ejection period/ejection time ratio in the postpremature beat was significantly $(p<0.001)$ lower than in the control beat by $\Delta($ PEP/ $\mathrm{ET})=-0 \cdot 10 \pm 0.05$ (range: -0.01 to -0.25 ). The change in total electrochemical systole in response to the postextrasystolic potentiation was $\Delta E M S=18 \pm 22 \mathrm{~ms}(\mathrm{p}<0.001)$.

The left ventricular outflow systolic pressure gradient rose from $\mathrm{Gc}=35.6 \pm 38.9 \mathrm{mmHg}$ (range: 0 to $130 \mathrm{mmHg}$ ) in the control beat to $\mathrm{Gx}=87 \cdot 8 \pm 69.3$ $\mathrm{mmHg}$ (range: 0 to $224 \mathrm{mmHg}$ ) in the postpremature beat, a significant increment of $\Delta \mathrm{G}=52.2 \pm 38.9$ mmHg (range: 0 to $146 \mathrm{mmHg}$ ).

There was poor correlation between either $\triangle \mathrm{PEP}$ or $\Delta(\mathrm{PEP} / \mathrm{ET})$, and the gradients $\mathrm{Gc}, \mathrm{Gx}$, and $\Delta \mathrm{G}$ (Table $2)$. In contrast, significant $(p<0.001)$ linear correlations were found between $\triangle E M S$ and either Gc $(\mathrm{r}=0.483), \mathrm{Gx}(\mathrm{r}=0.728)$, or $\Delta \mathrm{G}(\mathrm{r}=0.813)$; and also between $\Delta \mathrm{ET}$ and either $\mathrm{Gc}(\mathrm{r}=0.426), \mathrm{Gx}(\mathrm{r}=0.720)$,

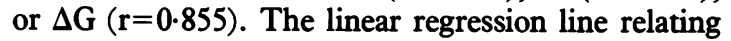
$\Delta \mathrm{ET}$ and $\Delta$ was (Fig. 3):

$$
\Delta \mathrm{G}=1.65 \Delta \mathrm{ET}-9
$$

where $\Delta \mathrm{G}$ and $\Delta \mathrm{ET}$ are expressed in $\mathrm{mmHg}$ and $\mathrm{ms}$, respectively.

The Brockenbrough sign, ${ }^{11}$ a decrease in aortic pulse pressure in the first postpremature beat as compared with the control sinus beat, was seen in only $60 \%(45 / 75)$ of postextrasystolic potentiation events. The sign was consistently present in nine patients (36\%) and consistently absent in eight patients (32\%). In the remaining eight patients (32\%) it was present in some postextrasystolic potentiation events and absent in others, during the same study.

\section{Discussion}

In patients with hypertrophic cardiomyopathy, the lack of correlation between symptoms, ${ }^{12}$ rhythm disturbances, ${ }^{13}$ and mortality, ${ }^{14}$ on the one hand, and 


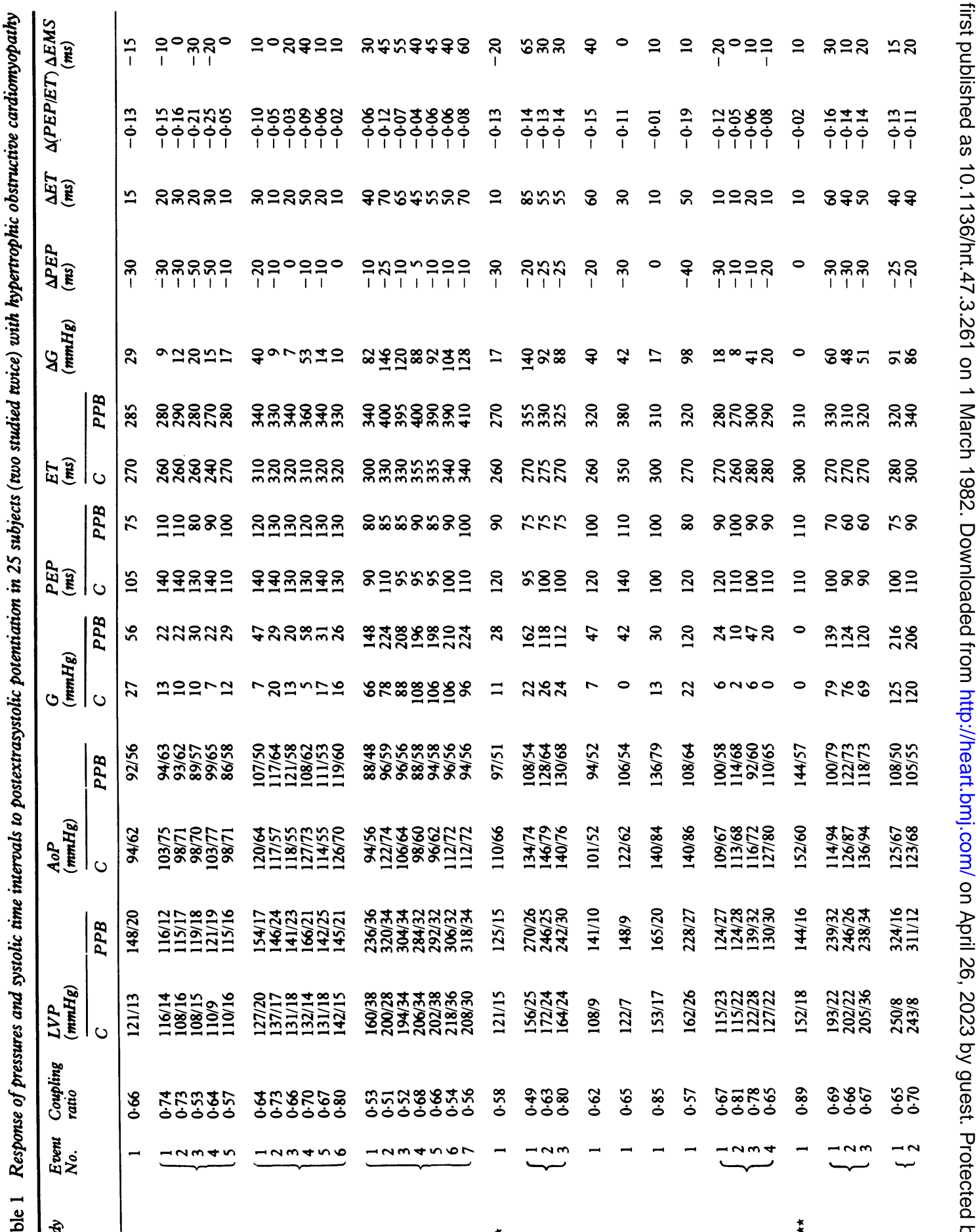




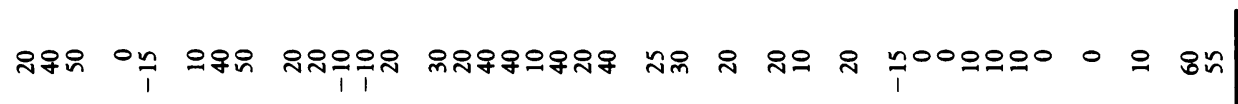

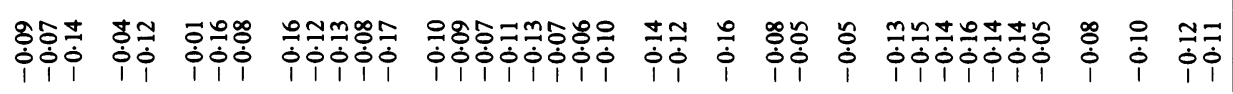

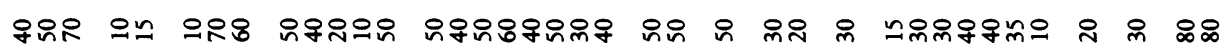

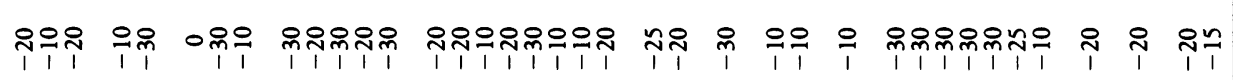

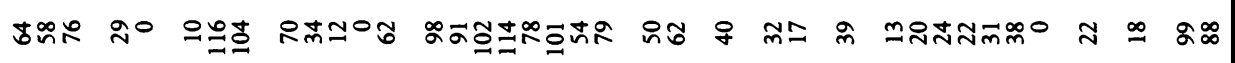

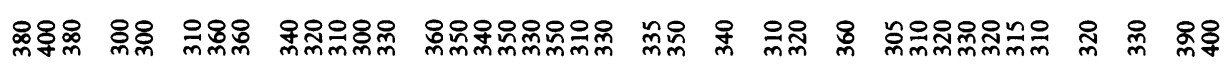

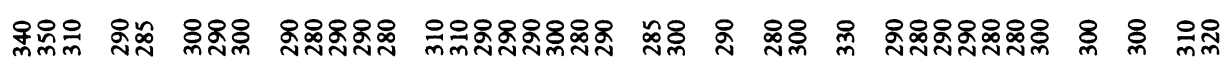

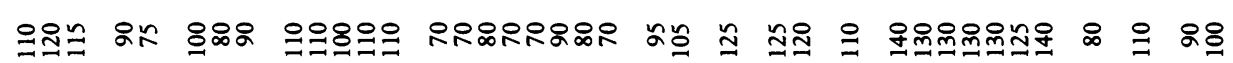

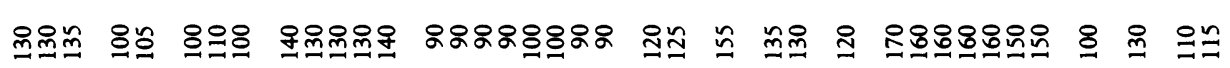

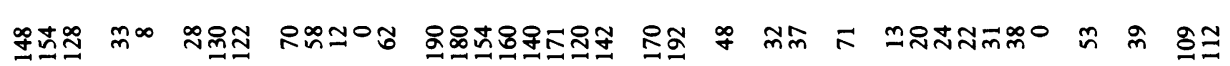

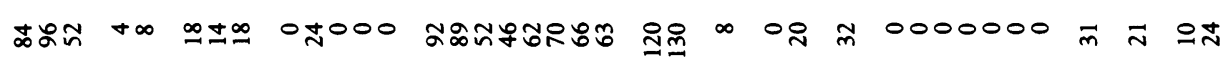

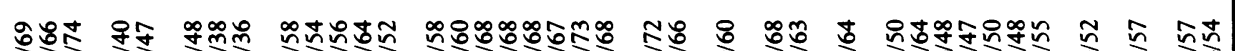

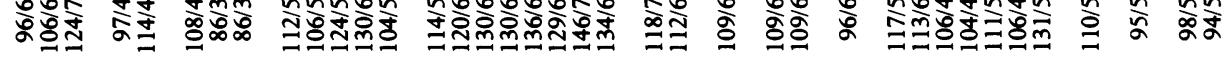

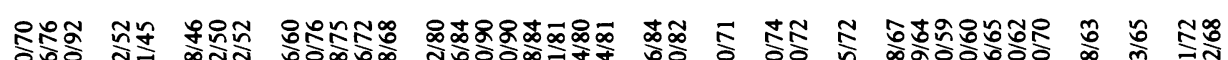

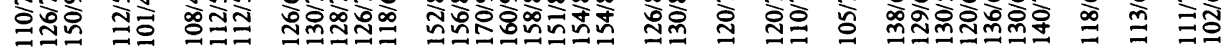

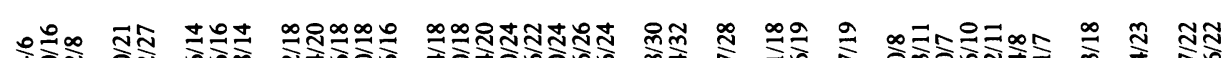

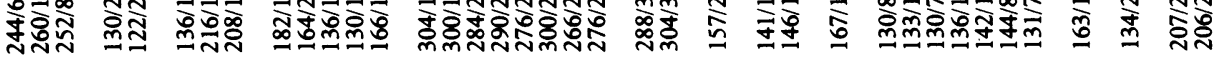

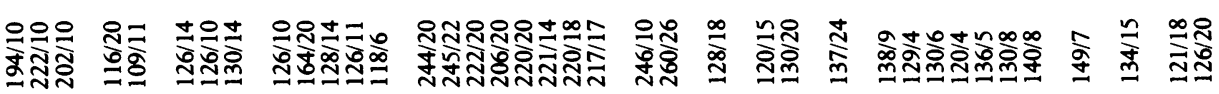

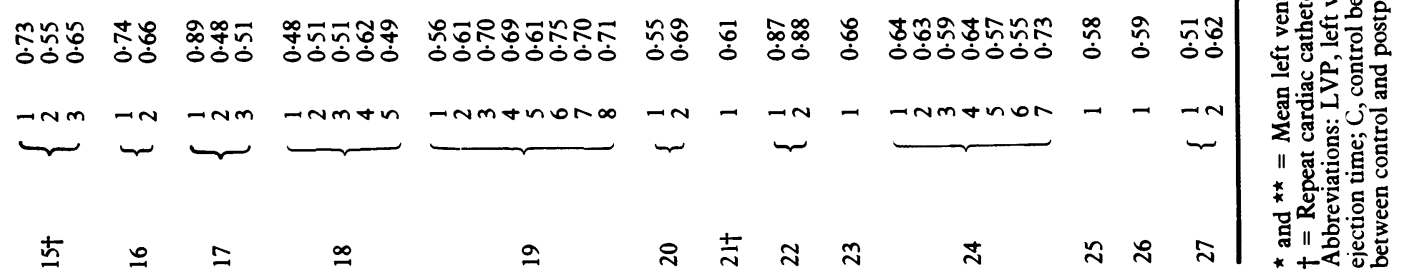


Table 2 Statistical matrix relating left ventricular outflow pressure gradients and postextrasystolic changes in systolic time intervals in hypertrophic cardiomyopathy

\begin{tabular}{|c|c|c|c|c|}
\hline & $\begin{array}{l}\triangle P E P \\
(-20 \pm 11) \\
(m s)\end{array}$ & $\begin{array}{l}\Delta E T \\
(37 \pm 20) \\
(m s)\end{array}$ & $\begin{array}{l}\triangle(P E P / E T) \\
(-0.10 \pm 0.05)\end{array}$ & $\begin{array}{l}\triangle E M S \\
(18 \pm 22) \\
(m s)\end{array}$ \\
\hline $\begin{array}{l}\mathrm{Gc} \\
(35.6 \pm 38.9 \mathrm{mmHg}) \\
\mathrm{Gx} \\
(87.8 \pm 69.3 \mathrm{mmHg}) \\
\Delta \mathrm{G} \\
(52.2 \pm 38.9 \mathrm{mmHg})\end{array}$ & $\begin{array}{l}r=0.151 \\
r=0.100 \\
r=0.028\end{array}$ & $\begin{array}{l}r=0.426^{\star} \\
r=0.720^{\star} \\
r=0.855^{\star}\end{array}$ & $\begin{array}{l}r=0.109 \\
r=-0.002 \\
r=-0.112\end{array}$ & $\begin{array}{l}r=0.483^{\star} \\
r=0.728^{\star} \\
r=0.813^{\star}\end{array}$ \\
\hline
\end{tabular}

Unmarked values for correlation coefficient ( $r$ ) are statistically insignificant $(p>0.05)$.

Abbreviations: same as in Table 1.

${ }^{\star} \mathrm{p}<0.001$.

resting left ventricular outflow pressure gradient, on the other, has cast doubt on the importance of the gradient either as a determinant of the severity of the disease or as a suitable target for specific treatment. Accordingly, the usefulness of measuring the gradient seems to be limited, except as a means of confirming the diagnosis. Other aspects of the disease, however, have been found to correlate with the presence and magnitude of the gradient (for example, incidence of bacterial endocarditis ${ }^{14}$ ). Furthermore, there is no information concerning the relation between any of the aforementioned attributes and the responsiveness of the gradient to positive inotropic stimulation, which is precisely what this method determines. Because of these considerations, we believe that information on the gradient and its response to provocation is welcome, particularly if it could be procured by non-invasive means.

The systolic gradient between the left ventricular and aortic pressures found in hypertrophic cardiomyopathy has been traditionally attributed to dynamic left ventricular outflow "obstruction", 15 16 though it can also be produced by left vertricular cavity "obliteration". ${ }^{17} 18$ Despite the fact that the postextrasystolic prolongation of ejection time invariably noted in this study represents a very strong argument supporting the "obstruction" theory, our use of the term "obstruction" need not be construed as denial of the existence of the phenomenon of "obliteration", at least in some patients. This study was not designed to provide evidence for or against either the "obstruction" or the "obliteration" theory. Instead, we attempted to establish whether the effect of the post-
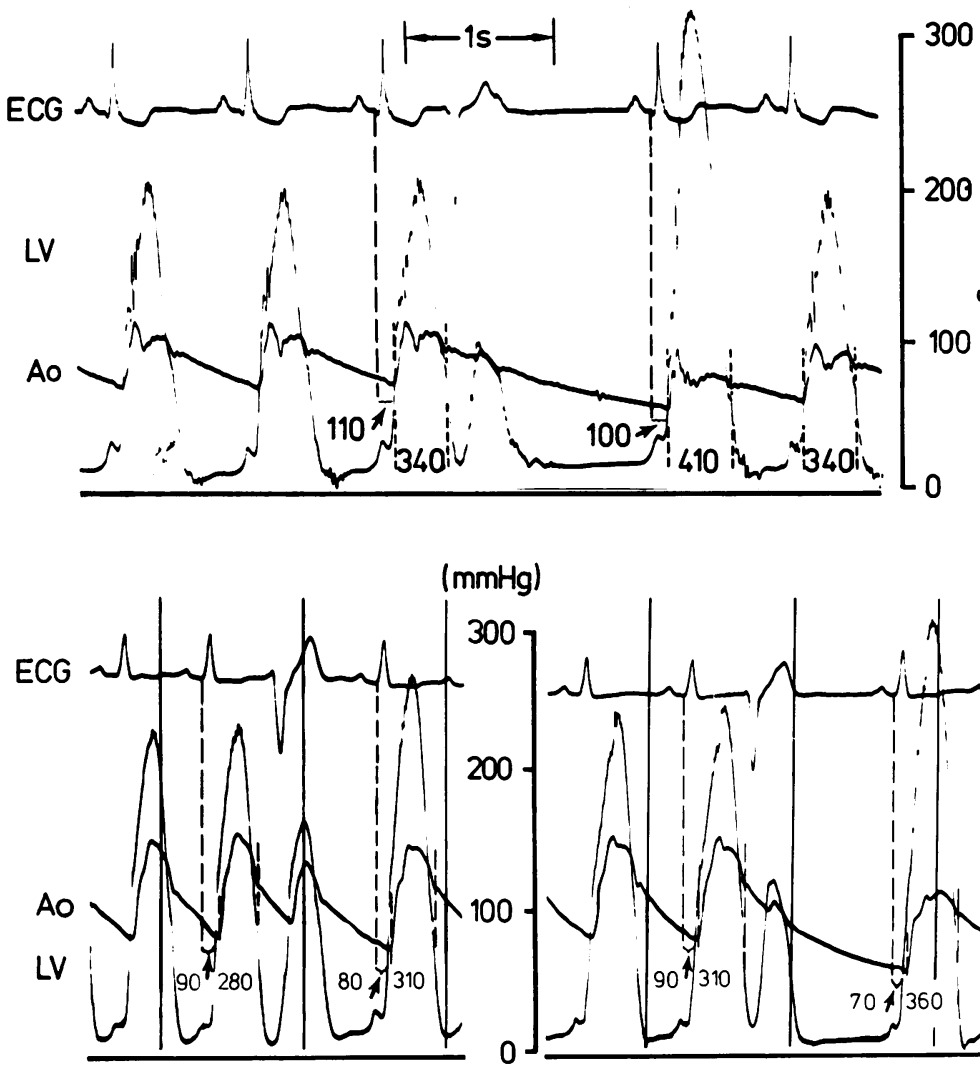

Fig. 1 Simultaneous recording of electrocardiogram (ECG), and pressures from the left ventricle $(L V)$ and aorta $(A)$ in case 4 . Note significant prolongation ( $70 \mathrm{~ms}$ ) of ejection time, associated with a large $(128 \mathrm{mmHg})$

$\overline{3}$ change in gradient from control to 3 postpremature beat. In this and the T⿱士口 lines on each cardiac cycle indicate, respectively, the onset of $Q$ wave, and the onset and termination of ejection time. Values for pre-ejection period and ejection time are also shown. The ECG and LV pressure signals were retouched for clarity.

Fig. 2 Recordings from case 19. Left: $a$ 음 modest $(30 \mathrm{~ms})$ prolongation in ejection time and a $10 \mathrm{~ms}$ abbreviation in pre-ejection period are seen, associated with a $58 \mathrm{~mm} \mathrm{Hg}$ increase in gradient from the control to the postextrasystolic beat. Right: later during same catheterisation. Note severe ( $50 \mathrm{~ms}$ ) prolongation in ejection time and $20 \mathrm{~ms}$ abbreviation in pre-ejection period, in association with significant ( $98 \mathrm{~mm} \mathrm{Hg}$ ) increase in gradient in response to postextrasystolic potentiation. The left ventricular and aortic pressure signals were retouched, and a dP/dt and pulmonary "wedge" pressure signals were removed for clarity.

Abbreviations same as in Fig. 1. 


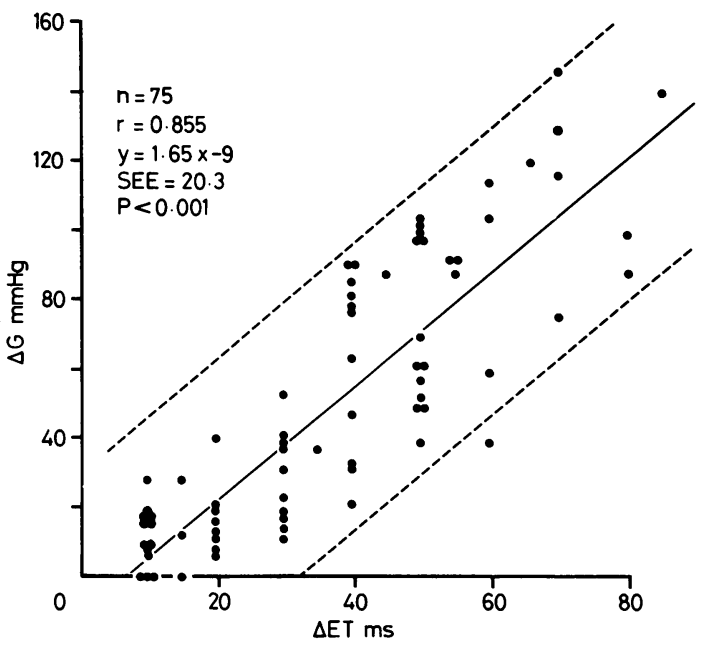

Fig. 3 The relation between prolongation in ejection time $(\Delta E T)$ and change in ventricular aortic pressure gradient $(\Delta G)$ observed in 75 instances of postextrasystolic potentiation in 25 patients. The solid line is the regression line whose equation is given. The dashed lines are drawn two standard errors of estimate $(S E E)$ from regression line and define a confidence interval of $95 \%$. $n$, number of observations; $r$, correlation coefficient; $P$, level of statistical significance.

extrasystolic potentiation on the systolic time intervals provides quantitative information on the left ventricular outflow pressure gradient, and its responsiveness to provocation, whatever their haemodynamic or clinical significance might be.

The phenomenon of postextrasystolic potentiation has been extensively studied. ${ }^{819-24}$ In comparison with the control beat, the first postpremature beat is a "stronger" beat, caused mainly, if not exclusively, ${ }^{23} 24$ by the enhanced left ventricular inotropic state and to a lesser extent, if at all, by the increased preload and diminished afterload associated with the long postextrasystolic pause. It should be noted that the role of the Starling's effect in the postextrasystolic potentiation phenomenon remains controversial since a statistically significant increase in end-diastolic volume in the potentiated beat has been found by some $^{2122}$ but not all ${ }^{2324}$ investigators. As a result of this combination, the first postpremature beat is characterised by an abbreviated pre-ejection period resulting from the left ventricular pressure rising at a faster rate $(\mathrm{dP} / \mathrm{dt})$ to travel the diminished enddiastolic difference between left ventricular and aortic pressure. This response of the pre-ejection period to the postextrasystolic potentiation has been previously observed by us in the unobstructed left ventricle, whether normal or failing, ${ }^{9}$ and was also seen in the ventricle with dynamic left ventricular obstruction, in this series.
The effect of postextrasystolic potentiation on the duration of left ventricular ejection varies according to the presence or absence of failure and the existence and nature of obstruction to left ventricular ejection, and can be explained by reference to similar experience from the use of other positive inotropic agents. ${ }^{25-27}$ Because of the aforementioned combination of increased left ventricular inotropic state and possibly preload, and the diminished afterload at the onset of ejection, the potentiated beat is characterised by an increased velocity of fibre shortening (ejection rate) which tends to abbreviate the duration of ejection, and by an increased extent of fibre shortening (stroke volume) which tends to prolong the ejection time. In the absence of obstruction to left ventricular ejection, the effect of increased ejection rate predominates and the ejection time shortens or, at least, remains unchanged in the potentiated beat. ${ }^{9}$ The opposite, however, may occasionally be the case with the unobstructed but severely failing ventricle where the substantial increase in stroke volume prevails and results in a prolongation in the ejection time. ${ }^{927}$

In the case of the nonfailing but obstructed ventricle the effect of postextrasystolic potentiation on the duration of ejection is somewhat different. First, the compliance of chronically obstructed ventricles is so diminished that prolongation of diastole beyond normal makes little or no difference to their end-diastolic volume. Second, the end-systolic volume of these ventricles is usually too small to permit a substantial increase in stroke volume by way of a more complete left ventricular emptying in the potentiated beat. As a result, the longer postextrasystolic pause and the increased contractility associated with postextrasystolic potentiation do not translate into a substantial increase in stroke volume in such ventricles. This has been shown in patients with hypertrophic cardiomyopathy whose stroke volume in the potentiated beat was found to be slightly larger, ${ }^{28}$ the same, ${ }^{29} 30$ or even smaller, ${ }^{29} 30$ as compared with other sinus beats. Given the augmented ejection rate of the potentiated beat, no prolongation of ejection would be expected from such modest changes in stroke volume, were it not for the presence of obstruction to left ventricular outflow with its prolonging effect on the duration of left ventricular ejection.

Although several investigators have studied the effect of certain pharmacological interventions on the duration of ejection in hypertrophic cardiomyopathy we could find only two reports containing observations on the effect of postextrasystolic potentiation on ejection time. In one of these reports a prolongation in ejection time in excess of $20 \mathrm{~ms}$ was found in the first postpremature beat over control, in all nine patients with provocable left ventricular outflow obstruction determined by carotid pulse morphology, by mitral 
valve echocardiogram or, in three patients, by pressure recording at catheterisation. ${ }^{31}$ Because of the small number of catheterised patients, no attempt was made to correlate the prolongation in ejection time with the left ventricular outflow pressure gradient or change in gradient in the postpremature beat. In the other study, a prolongation in ejection time in excess of $20 \mathrm{~ms}$ was observed in the first postpremature beat in 11 of 12 patients with hypertrophic cardiomyopathy; in the exceptional patient, no change in ejection time was noted. ${ }^{32}$ In agreement with these two studies we found prolongation in ejection time in the first postpremature beat in all our patients, ranging from 10 to $85 \mathrm{~ms}$. In addition, we found a significant correlation between the amount of prolongation in ejection time and the magnitude of both the left ventricular outflow pressure gradient in the postpremature beat and the change in gradient in response to this provocation. The fact that such correlation was not found in the series of White and Zimmerman ${ }^{32}$ could possibly be explained on the basis of two methodological differences between their study and ours. The first difference is the exclusion from our study of patients with mild to moderate left ventricular failure (ejection fraction 0.30-0.50); inasmuch as left ventricular failure is known to affect independently the response of ejection time to postextrasystolic potentiation, the inclusion of such patients in White and Zimmerman's study may have weakened the correlation. The second difference is the larger number of our observations.

Patients with small or no resting pressure gradient but with a large gradient elicited by provocative manoeuvres are likely to develop gradients under non-basal conditions such as the upright posture, muscular exercise, and the spontaneous fluctuations in the amount of circulating catecholamines and, therefore, should not be considered as having a benign form of the disease, at least as far as the left ventricular systolic function is concerned. In fact, in some institutions, their management is the same as that reserved for a patient with severe gradient at rest. ${ }^{33}$ Therefore, severe prolongation in ejection time in the postpremature beat in a patient with hypertrophic cardiomyopathy indicates the potential for development of severe obstruction under non-basal conditions, and may provide guidance on the need and extent of treatment specifically directed against it.

In conclusion, this study has shown that in hypertrophic cardiomyopathy, postextrasystolic potentiation results in a significant prolongation in left ventricular ejection time. This prolongation is directly related to the magnitude of both the left ventricular outflow gradient of the potentiated beat and the change in gradient induced by this inotropic intervention. Given the close correspondence between inter- nally and externally measured systolic time intervals, ${ }^{34}$ the results of this study provide the background for the non-invasive assessment of hyper- $\stackrel{\oplus}{+}$ trophic cardiomyopathy from the response of external $\bar{c}$ systolic time intervals to spontaneous or externally-induced premature contractions. ${ }^{35}$

\section{References}

1 Goodwin JF, Krikler DM. Arrhythmia as a cause of sud- $\vec{\circ}$ den death in hypertrophic cardiomyopathy. Lancet 1976; ii: $937-40$.

2 Canedo MI, Frank MJ, Abdulla AM. Rhythm disturbances in hypertrophic cardiomyopathy: prevalence, relation to symptoms and management. $\mathrm{Am}$ f Cardiol 1980; 45: 848-55.

3 Sutton MGSJ, Tajik AJ, Gibson DG, Brown DJ, Seward JB, Giuliani ER. Echocardiographic assessment of left $\stackrel{9}{9}$ ventricular filling and septal and posterior wall dynamics in idiopathic hypertrophic subaortic stenosis. Circulation 1978; 57: 512-20.

4 Sanderson JE, Traill TA, Sutton MGSJ, Brown DJ, Gibson DG, Goodwin JF. Left ventricular relaxation and filling in hypertrophic cardiomyopathy. An echocardiographic study. Br Heart $\mathcal{F}$ 1978; 40: 596-601.

5 Henry WL, Clark CE, Glancy DL, Epstein SE. $\stackrel{\infty}{N}$ Echocardiographic measurement of left ventricular outflow gradient in idiopathic hypertrophic subaortic stenosis. N Engl f Med 1973; 288: 989-93.

6 Gilbert BW, Pollick C, Adelman AG, Wigle ED. Hypertrophic cardiomyopathy: subclassification by $M$-mode echocardiography. Am $\mathcal{F}$ Cardiol 1980; 45: 861-72.

7 Stefadouros MA, Canedo MI, Karayannis E, Abdulla $\vec{P}$ AM, Frank MJ. Internally recorded systolic time intervals in hypertrophic subaortic stenosis. Am $\mathcal{F}$ Cardiol 1977; 40: 700-6.

8 Lendrum B, Feinberg H, Boyd E, Katz LN. Rhythm effects on contractility of the beating isovolumic left ventricle. Am f Physiol 1960; 199: 1115-20.

9 Stefadouros MA, Abdulla AM, Canedo MI. Postextrasystolic potentiation in the normal and the failing left 3 ventricle: a noninvasive study (abstract). Clin Res 1976; 24: 241.

10 Simon AL, Ross J Jr, Gault JH. Angiographic anatomy of the left ventricle and mitral valve in idiopathic hyper- 9 trophic subaortic stenosis. Circulation 1967; 36: 852-67. D

11 Brockenbrough EC, Braunwald E, Morrow EG. A 윽 hemodynamic technic for the detection of hypertrophic subaortic stenosis. Circulation 1961; 23: 189-94.

12 Braunwald E, Lambrew CT, Rockoff SD, Ross J, Mor- N row AG. Idiopathic hypertrophic subaortic stenosis: I. A N description of the disease based upon an analysis of $64 \mathrm{\omega}$ patients. Circulation 1964; suppl IV: 3-119.

13 Savage DD, Seides SF, Maron BJ, Myers DJ, Epstein 0 SE. Prevalence of arrhythmias during 24-hour elec- $\bar{\Phi}$ trocardiographic monitoring and exercise testing in $\stackrel{?}{+}$ patients with obstructive and nonobstructive hyper- 0 trophic cardiomyopathy. Circulation 1979; 59: 866-75.

14 Frank S, Braunwald E. Idiopathic hypertrophic subaor- $\mathbb{D}$ tic stenosis. Clinical analysis of 126 patients with $\frac{\vec{D}}{\mathbb{D}}$ emphasis on the natural history. Circulation 1968; 37: $\varrho$ 759-88. 
15 Wigle ED, David PR, Labrosse CJ, McMeekan J. Muscular subaortic stenosis: the interrelation of wall tension, outflow tract "distending pressure" and orifice radius. Am $\mathcal{F}$ Cardiol 1965; 15: 761-72.

16 Ross J Jr, Braunwald E, Gault JH, Mason DT, Morrow AG. The mechanism of the intraventricular pressure gradient in idiopathic hypertrophic subaortic stenosis. Circulation 1966; 34: 558-78.

17 Criley JM, Lewis KB, White RI Jr, Ross RS. Pressure gradients without obstruction. A new concept of "hypertrophic subaortic stenosis". Circulation 1965; 32: 881-7.

18 White RI Jr, Criley JM, Lewis KB, Ross RS. Experimental production of intracavity pressure differences. Possible significance in the interpretation of human hemodynamic studies. Am F Cardiol 1967; 19: 806-17.

19 Hoffman BF, Bindler E, Suckling EE. Postextrasystolic potentiation of contraction in cardiac muscle. Am $\mathfrak{F}$ Physiol 1956; 185: 95-102.

20 Hoffman BF, Bartelstone HJ, Scherlag BJ, Cranefield PF. Effects of postextrasystolic potentiation on normal and failing hearts. Bull N Y Acad Med 1965; 41: 498534.

21 Dyke SH, Cohn PF, Gorlin R, Sonnenblick EH. Detection of residual myocardial function in coronary artery disease using postextrasystolic potentiation. Circulation 1974; 50: 694-9.

22 Banka VS, Bodenheimer MM, Shah R, Helfant RH. Intervention ventriculography: comparative value of nitroglycerin, postextrasystolic potentiation and nitroglycerin plus post-extrasystolic potentiation. Circulation 1976; 53: 632-7.

23 Gaasch WH, Bing OHL, Cole JS, Hanley HG. Postextrasystolic compliance of the left ventricle. Circulation 1977; 56: 540-4.

24 Sung CS, Mathur VS, Garcia E, De Castro CM, Hall RJ. Is postextrasystolic potentiation dependent on Starling's law? Circulation 1980; 62: 1032-5.

25 Salzman SH, Wolfson S, Jackson B, Schechter, E. Epinephrine infusion in man. Standardization, normal response, and abnormal response in idiopathic hypertrophic subaortic stenosis. Circulation 1971; 43: 137-44.
26 Weissler AM, Snyder JR, Schoenfeld CD, Cohen S. Assay of digitalis glycosides in man. Am $\mathcal{F}$ Cardiol 1966; 17: 768-80.

27 Weissler AM, Schoenfeld CD. Effect of digitalis on systolic time intervals in heart failure. Am $\mathcal{F}$ Med Sci 1970; 259: 4-20.

28 Rackley CE, Whalen RE, McIntosh HD. Ventricular volume studies in a patient with hypertrophic subaortic stenosis. Circulation 1966; 34: 579-84.

29 Hernandez RR, Greenfield JC Jr, McCall BW. Pressure flow studies in hypertrophic subaortic stenosis. $\mathcal{f}$ Clin Invest 1964; 43: 401-7.

30 Pierce GE, Morrow AG, Braunwald E. Idiopathic hypertrophic subaortic stenosis. III. Intraoperative studies on the mechanism of obstruction and its hemodynamic consequences. Circulation 1964; 30; suppl 4: V152.

31 Angoff GH, Wistram D, Sloss LJ, et al. Value of a noninvasively induced ventricular extrasystole during echocardiographic and phonocardiographic assessment of patients with idiopathic hypertrophic subaortic stenosis. Am $\mathcal{F}$ Cardiol 1978; 42: 919-24.

32 White CW, Zimmerman TJ. Prolonged left ventricular ejection time in the post-premature beat. A sensitive sign of idiopathic hypertrophic subaortic stenosis. Circulation 1975; 52: 306-12.

33 Epstein SE, Morrow AG, Henry WL, Clark CE. The role of operative treatment in patients with idiopathic hypertrophic subaortic stenosis. Circulation 1973; 48: 677-80.

34 Van De Werf F, Piessens J, Kesteloot H, De Geest H. A comparison of systolic time intervals derived from the central aortic pressure and from the external carotid pulse tracing. Circulation 1975; 51: 310-6.

35 Cohn PF, Angoff GH, Zoll PM, et al. A new, noninvasive technique for inducing post-extrasystolic potentiation during echocardiography. Circulation 1977; 56: $598-605$.

Requests for reprints to Professor Miltiadis A Stefadouros, Department of Medicine, Medical College of Georgia, Augusta, Georgia 30912, USA. 